\title{
CONTROLLING PRECIPITATION OF ALLOY 718 WITH DIFFERENT Nb CONTENT AND RELEVANT EFFECT ON MECHANICAL BEHAVIOUR
}

\author{
Oriana Tassa ${ }^{1}$, Laura Alleva ${ }^{1}$, Arianna Gotti ${ }^{1}$, Jutta Kloewer ${ }^{2}$, Ali Aghajani ${ }^{2}$ \\ ${ }^{1}$ Centro Sviluppo Materiali S.p.A., Via di Castel Romano 100, 00128, Rome, Italy \\ ${ }^{2}$ ThyssenKrupp VDM GmbH, Kleffstraße 23, 58762 Altena, Deutschland Keywords: IN718,
}

Heat treatment, Mechanical properties, Delta phase, Precipitation modeling

\begin{abstract}
In oil and gas fields high levels of hydrogen sulphide, carbon dioxide, chloride and sulphur at high pressures and high temperatures require material fine tuning in terms of chemical composition, microstructure and mechanical properties to assure required stress corrosion cracking resistance. 718 alloy is applied in various components operating in severe environments. Pilot scale production has been realised, with a narrow control of $\mathrm{Nb}$ content (4.8-5.2 mass $\%$ ) to investigate chemical composition effect on material properties, for different heat treatments. SEM/FEG and TEM investigations have been carried out. The results give correlations between $\mathrm{Nb}$ content and hardness, tensile strength and ductility. Heat-treatment strongly affects grain boundaries delta-phase formation, volume fraction and mean size of fine precipitates inside grains.
\end{abstract}

To better understand experimental results thermodynamic and kinetic calculations have been performed: results by MatCalc and JMatPro commercial software are compared and discussed in order to have information on reliability and applicability of these models.

\section{Introduction}

Age-hardenable alloys are used as corrosion resistant materials in the oil and gas industry because of their combination of high strength, corrosion resistance, and ability to be heat treated to various strength levels. Nickel-base alloys 718, 725, and 925 are commonly used in oil and natural gas production [1]. Components used in these severe environments must resist SCC. The potential for SCC becomes greater with increasing temperature and concentrations of $\mathrm{H}_{2} \mathrm{~S}$ and the presence of chloride ions and elemental sulfur.

Alloy strength is another factor. As strength increases, environmental cracking susceptibility also increases. A proper material design is required to achieve the optimum level of strength, ductility, toughness and cracking resistance.

These alloys contain high $\mathrm{Cr} / \mathrm{Mo}$ levels for preventing aqueous corrosion, and also considerable levels of hardeners like $\mathrm{Ti} / \mathrm{Nb} / \mathrm{Al}$ to form gamma prime and gamma double prime precipitates for improving strength. Being heavily alloyed multi-component systems, these materials require special solutions for processing and heat treatments. Several new alloys have been developed for 
this particular purpose [1-3]; nevertheless alloy 718 is the most widely applied in certain sour gas environments. The stress corrosion behaviour of alloy 718 is strongly affected by the microstructure of the material. It is therefore, important to identify those specific microstructural features that are associated with a good performance and with poor performance, and then to design an appropriate thermal treatment to produce the optimum microstructure to assure a good stress corrosion resistance.

Time-Temperature-Transformation (TTT) diagrams can be used as road maps to determine precipitation of various phases under different processing conditions

The aim of this paper is to evaluate the effect of Niobium content and ageing treatments on final properties (hardness, tensile properties and impact behaviour) by studying their influence on microstructure and on precipitation state.

Additionally, these experimental investigations are implemented by precipitation calculations carried out with the thermo-kinetic commercial software MatCalc [4] and JMat-Pro [5].

\section{Materials and Experimental Method}

Three IN718 heats were produced with low, intermediate and high $\mathrm{Nb}$ content: $80 \mathrm{Kg}$ ingots produced by VIM were remelted in VAR plant to manufacture ingots with the following size: $350 \mathrm{~mm}$ length, $150 \mathrm{~mm}$ diameter, $50 \mathrm{Kg}$ weight. The VAR ingots (fig. 1a) were hot rolled to manufacture $16 \mathrm{~mm}$ thick plates (fig. 1b). Before hot roll, VAR ingots were heat treated to reduce microsegregation and to dissolve second phases and eutectics (maximum temperature of $\left.1190^{\circ} \mathrm{C}\right)$.
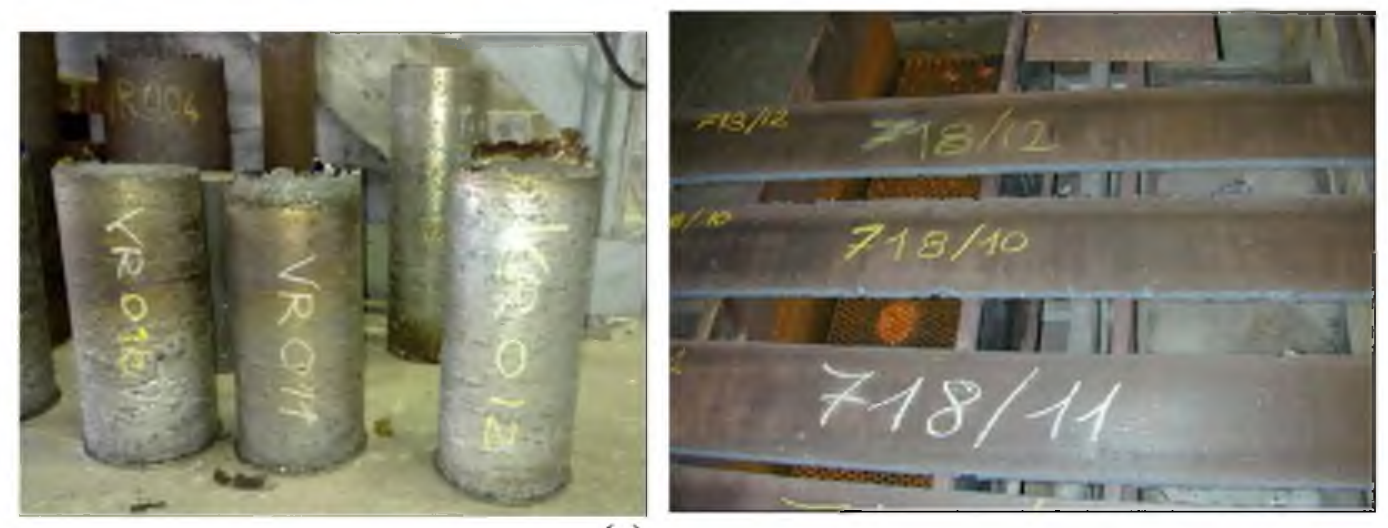

(a)

Figure 1. VAR ingots (a) and hot rolled plates (b)

The chemical composition has been measured in the top and bottom areas of each electrode. The results shown in Table I, evidence the high chemical homogeneity.

Transverse specimens have been machined from the hot rolled, solution and age heat treated plates. As rolled and solutioned specimens have been assessed by Optical Microscope(OM), while aged specimens have been analyzed by Optical Microscope and Scanning Electron Microscope (SEM). Selected specimens (solutioned and aged) have been investigated by SEM/FEG. Metallographic samples have been etched by using "Seven acid" and "Kalling's 2" etchants. 
Table I. Chemical composition of produce VAR ingots

\begin{tabular}{|c|c|l|l|l|l|l|l|l|}
\hline Ingot & Position & $\mathrm{C}$ & $\mathrm{Ti}$ & $\mathrm{Cr}$ & $\mathrm{Fe}$ & $\mathrm{Mo}$ & $\mathrm{Nb}$ & $\mathrm{Ni}$ \\
\hline VR 010 & top & 0.020 & 0.93 & 18.5 & 19.1 & 3.03 & 4.77 & $\mathrm{Bal}$ \\
\cline { 2 - 10 } & bottom & 0.021 & 0.96 & 18.4 & 18.9 & 3.03 & 4.87 & $\mathrm{Bal}$ \\
\hline \multirow{2}{*}{ VR 011 } & top & 0.026 & 0.93 & 18.2 & 20.2 & 2.91 & 5.06 & Bal \\
\cline { 2 - 9 } & bottom & 0.021 & 0.97 & 18.5 & 18.7 & 3.01 & 5.09 & Bal \\
\hline \multirow{2}{*}{ VR 012 } & top & 0.018 & 0.93 & 18.4 & 18.7 & 2.98 & 5.25 & Bal \\
\cline { 2 - 9 } & bottom & 0.019 & 0.97 & 18.5 & 19 & 2.95 & 5.32 & Bal \\
\hline
\end{tabular}

The same solution heat treatment $\left(1030^{\circ} \mathrm{C}\right.$ for 1 hour/water quenching), has been performed for each hot rolled plate, irrespectively of $\mathrm{Nb}$ content.

Four different ageing treatments have been performed:

- A: $780^{\circ} \mathrm{C} / 6 \mathrm{~h}$ for all the three compositions;

- B: $760^{\circ} \mathrm{C} / 4 \mathrm{~h}$ for $\mathrm{Nb}=5 \% \mathrm{wt}$;

- C: $720^{\circ} \mathrm{C} / 8 \mathrm{~h}+620^{\circ} \mathrm{C} / 8 \mathrm{~h}$ for $\mathrm{Nb} 5 \mathrm{wt} \%$;

- D: $790^{\circ} \mathrm{C} / 8 \mathrm{~h}$ for $\mathrm{Nb} 5 \mathrm{wt} \%$.

The last treatment was performed only with the aim to investigate the effect of highest ageing temperature on precipitation state.

A few aged specimens (thin films) have been analyzed by Trasmission Electron Microscope TEM JEM-3200FS Field Emission Microscope, operating at $300 \mathrm{kV}$, equipped with high resolution EDS microanalysis, to better discriminate precipitates at grain boundaries and intragranular precipitates.

Specimens have been machined from aged plate, except for D treatment to produce two longitudinal tensile specimens $(\Phi=12 \mathrm{~mm}$ ) for room temperature tensile tests (according to ASTM E8 / E8M - 09).

On as rolled, solutioned and aged plates, microhardness was measured (HV $10 \mathrm{~kg}$ ) in different positions across the thickness of the plates. HV10 measurements have been then converted to HRC measurements.

\section{Results}

\section{$\underline{\text { Microstructure }}$}

Microstructure after hot rolling is characterised by a bimodal grain structure consisting of fine gamma grains (4-6 $\mu \mathrm{m})$ and coarse elongated non recrystallysed areas (with a length up to 570 $\mu \mathrm{m})$ as shown in fig. 2a. After solution treatments the samples show a homogeneous gamma phase microstructure with average grain size in the range 40-60 $\mu \mathrm{m}$. By OM analysis no continuous network of precipitates at grain boundaries, unusual microstructural features, nor acicular precipitates were observed. Some isolated particles have been detected (fig 2b). Microstructure of aged plates does not differ from solutioned microstructure (figure 2c). 


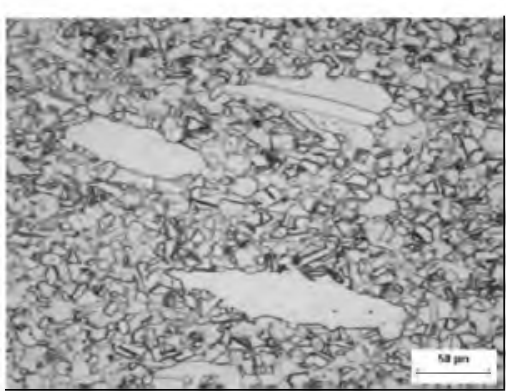

(a)

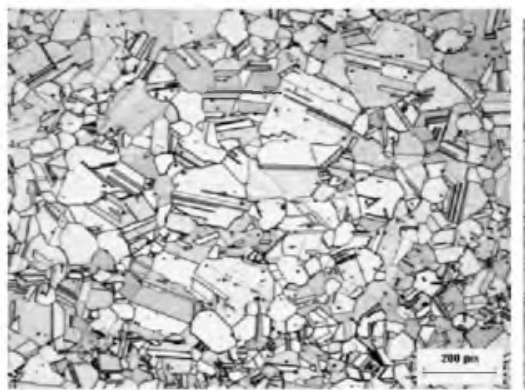

(b)

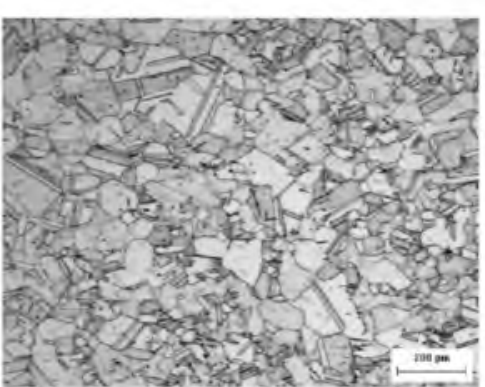

(c)

Figure 2. LM microstructure of (a) as rolled sample VR010; (b) solubilized plate VR012-A;

(c) aged plate VR011-A

Precipitate analysis was performed by SEM/EDS: larger precipitates (up to a size of $10 \mu \mathrm{m}$ ) are titanium nitrides and niobium carbides, sometimes associated in clusters. These intragranular precipitates have been formed at the highest temperatures, also in the liquid phase (figure 3a). Precipitates at grain boundaries have been better analysed by SEM/FEG (fig. 3b-c): the EDS analysis shows a $\mathrm{Nb}$ enrichment associable to delta phase. A finer precipitation inside the grains is evidenced too. In the case of the specimen VR011D aged at $790^{\circ} \mathrm{C}$ for $8 \mathrm{~h}(\mathrm{Nb} 5 \mathrm{wt} \%)$ gamma grain boundaries appear more covered by delta phase with respect to the other investigated experimental alloys.

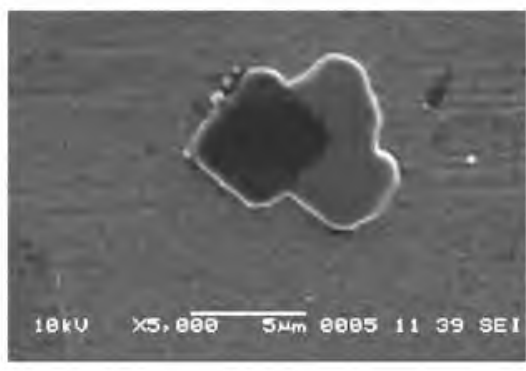

(a)

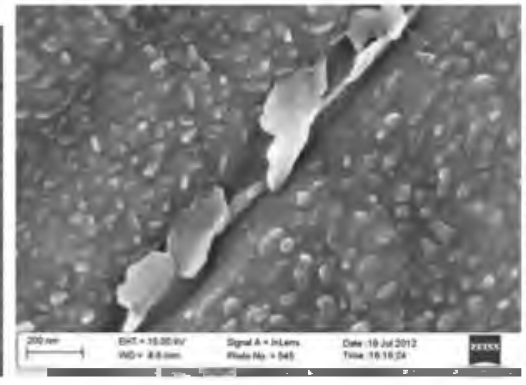

(b)

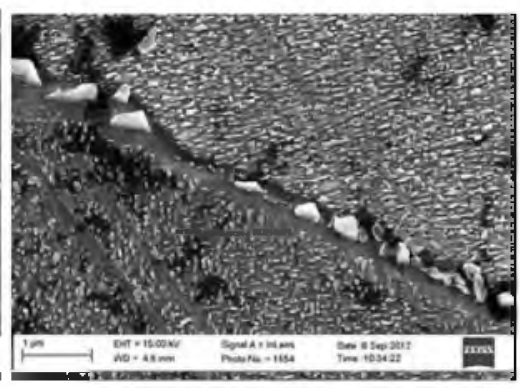

(c)

Figure 3. Precipitates in aged samples (a) coarse precipitates in VR010 sample by SEM (b) grain boundaries precipitates in VR011A sample by SEM/FEG; c) grain boundaries precipitates in VR011D sample by SEM/FEG

The nature of precipitates at gamma grain boundaries has been better defined by TEM investigations (figure 4), confirming delta phase nature also by diffraction patterns. 


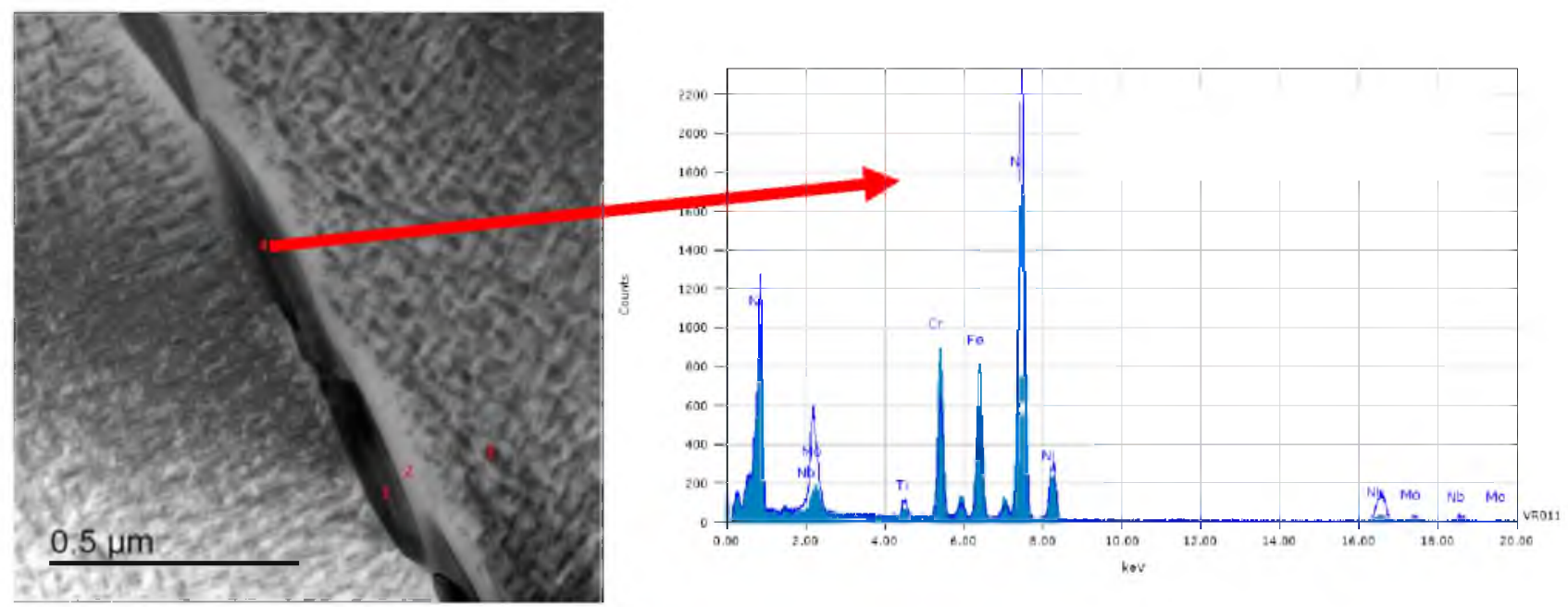

Figure 4. Grain boundaries precipitates by TEM/EDS analysis in VR011B aged sample

The nanometric precipitation inside the grains has been analysed and measured by TEM investigations: representative details of the fine precipitates are reported in figure 5a-b. Precipitates inside grains are mainly elongated particles, and EDS analysis revealed an enrichment in Nickel and Niobium: diffraction pattern associated to EDS analyses confirms that these precipitates are $\mathrm{Ni}_{3} \mathrm{Nb} \gamma$ '. Very fine precipitates are observable besides $\gamma^{\prime}$, that could be $\gamma^{\prime}$ particles. Due to their very small size $(<5 \mathrm{~nm})$, it was not possible to discriminate these particles from the matrix by thin film analysis.

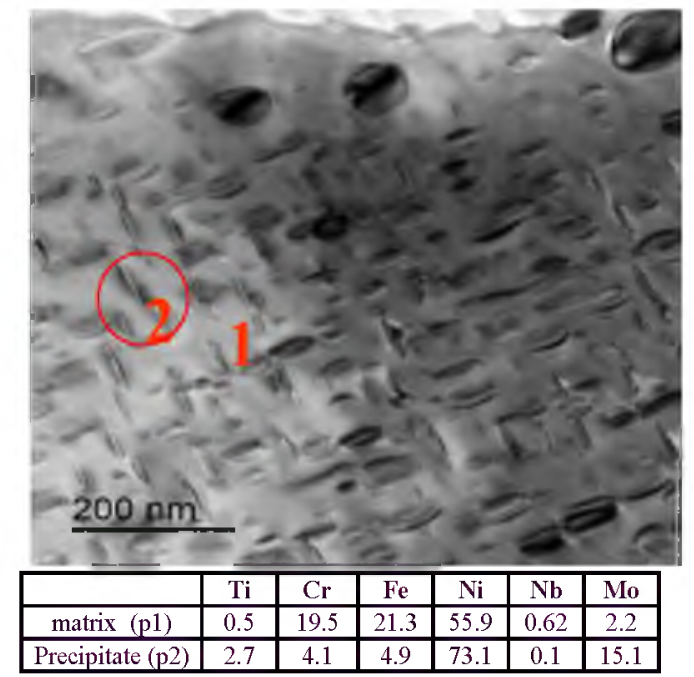

(a)

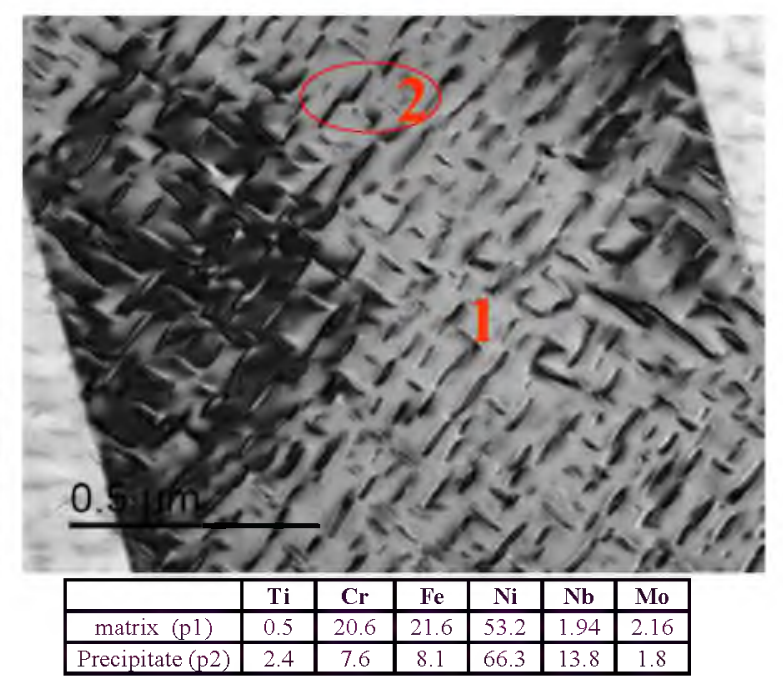

(b)

Figure 5. TEM micrographs showing $\gamma$ ' precipitates: (a) VR010 A (b) VR11A

Mean size of the $\gamma^{\prime}$ 'major axis particles are reported in Table II: precipitates range from 38 to 42 $\mathrm{nm}$ in specimens aged at $780^{\circ} \mathrm{C}$ for 6 hours, irrespective of the $\mathrm{Nb}$ content. The size is increased up to $58 \mathrm{~nm}$ by increasing ageing temperature and time (VR011D), and is decreased to $33 \mathrm{~nm}$ for lower ageing temperatures and times. 
Table II. Average size of $\gamma$ ' precipitates

\begin{tabular}{|c|c|}
\hline Sample & Average size (nm) \\
\hline VR010A & 38.7 \\
\hline VR011A & 41.9 \\
\hline VR011B & 32.6 \\
\hline VR011 D & 57.7 \\
\hline VR012 A & 38.0 \\
\hline
\end{tabular}

\section{$\underline{\text { Mechanical tests }}$}

The results of tensile tests are shown in figure $6 . \mathrm{YS}_{0.2 \%}$ and UTS are measured by the stress/strain curve; $\mathrm{El} \%$ and $\mathrm{RA} \%$ are the elongation at rupture and reduction of area measured on the specimens after the failure.

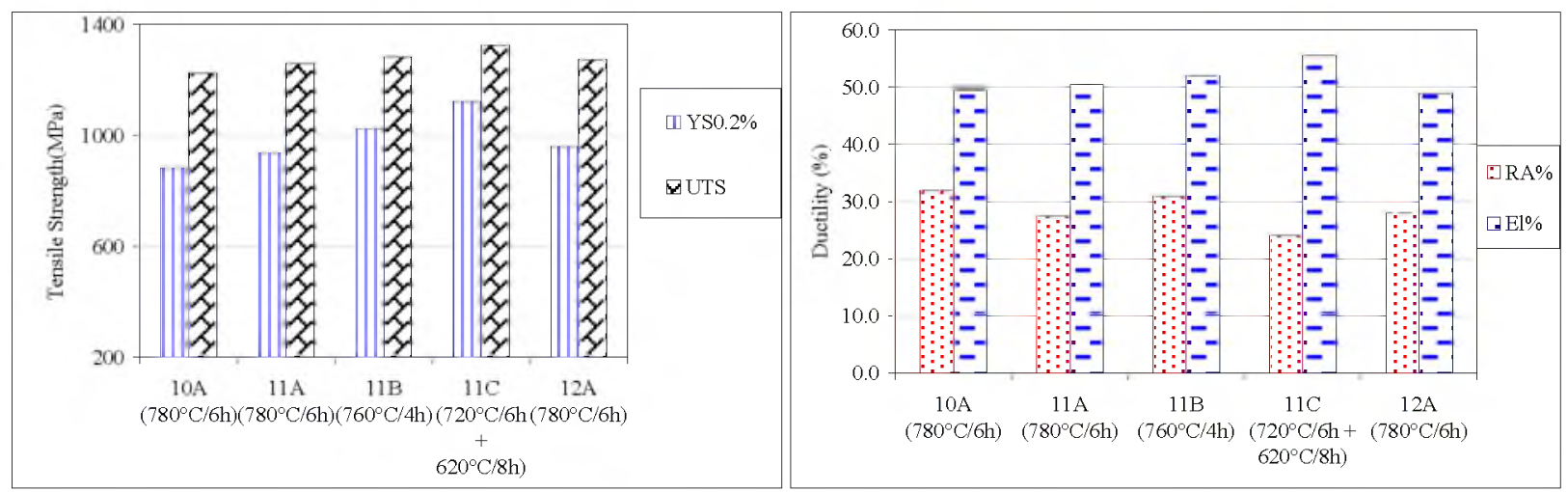

Figure 6. Tensile test results

Mechanical properties satisfy the acceptance criteria reported in the standard (UNS N07718) for plates with this thickness $\left(827 \mathrm{MPa}<\mathrm{YS}_{0.2}<1000 \mathrm{MPa}\right.$; UTS $>1034 \mathrm{MPa}$; El\%>20; RA\%>35\%). Yield and Tensile strength increases with Niobium content and for the ageing treatments performed at lower temperatures. Elongation to fracture (El\%) and reduction of area (RA\%) are comparable among the different specimens: the effect of Niobium content is very weak with $\mathrm{A} \%$ and $\mathrm{Z} \%$ decreasing as Niobium is increased. Decreasing the ageing treatment temperature, RA\% is increased. The effect of ageing temperature on $\mathrm{El} \%$ is not significant. The lowest values of El\% $(24 \%)$ have been found for the specimen taken from the plates aged at the lowest temperatures.

Hardness measurements (HV10) have been performed on aged plates, at $1.5 \mathrm{~mm}$ from the outer surfaces and at mid thickness. The effect of the chemical composition for the ageing condition "A" $\left(780^{\circ} \mathrm{C} \times 6 \mathrm{~h}\right)$ and of the different ageing conditions for the chemical composition VR011 $(\mathrm{Nb}=5 \%)$ are visible in the histograms of figure 7. Hardness is higher as the $\mathrm{Nb}$ content is increased, and as the temperatures of the ageing treatment is decreased. 


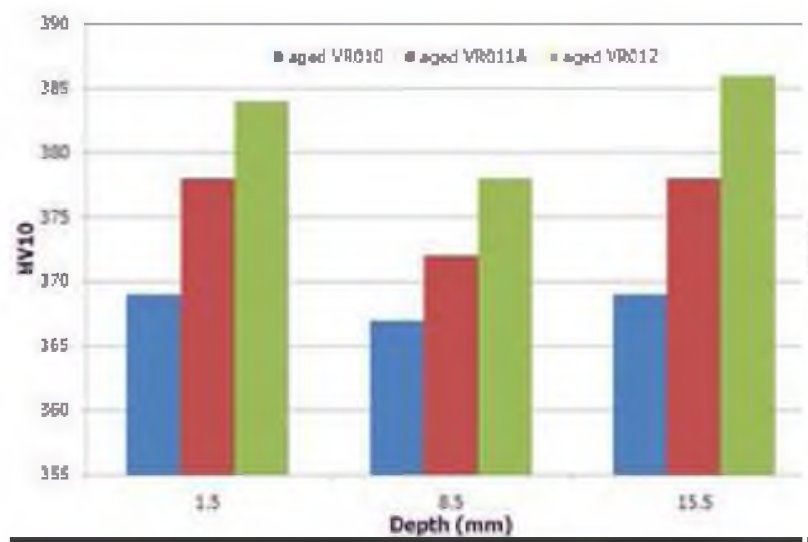

(a)

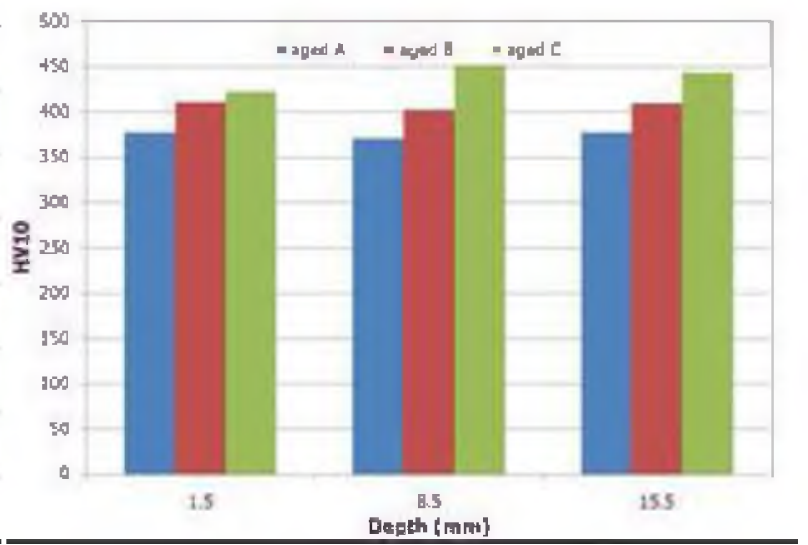

(b)

Figure 7. Effect on hardness of : ( a) chemical composition, with "A" ageing; (b) Nb content for VR011 composition)

\section{Microstructure prediction by models}

Commercial software have been used to predict equilibrium phases and precipitation kinetics, JMatPro 4.1 and MatCalc ver.5.4. Results have been compared to evaluate the accuracy of their databases.

JMatPro calculations have been performed by using TTNI5 database. For MatCalc simulations, the following database has been used: mc_ni_v1.013.tdb for thermodynamics and mc_ni.ddb for kinetics.

The results of equilibrium calculations are shown in Table III for the main phases. Precipitation temperatures are shown, as well as equilibrium fractions at the heat treatment temperatures. Equilibrium phase diagrams have been determined, for both models, by inhibiting delta $(\delta)$ and eta $(\eta)$ phases, that are generally formed for long ageing times. According to literature, Temperature-Time-Transformation diagrams the heat treatment conditions investigated in this activity should give $\delta$ and $\eta$ free structures [6-7]. Precipitation of gamma prime in the heat treatment conditions should be also absent [7]

Kinetic calculations have been performed by considering the complete heat treatment consisting of solubilisation and precipitation steps. The phases considered are $\gamma^{\prime \prime}, \gamma^{\prime}$, and $\delta$ phase. MC carbide are predicted to be formed by both models at temperature above the solution temperature with a stable fraction and size.

In figure 8, the phase fraction evolution during heat treatment is reported for the material VR 010. The heat treatment cycle is superimposed on the phase fraction curve. Precipitation of $\gamma^{\prime}$ is practically absent except for the transitory heat treatment steps. 
Table III. Comparison of Matcalc and JMatPro - "equilibrium" calculation results

\begin{tabular}{|c|c|c|c|c|c|c|c|c|c|c|c|}
\hline & & & & ATCA & & & & & IAT & & \\
\hline Alloy & $\begin{array}{c}\mathrm{Nb} \\
(\mathrm{wt} \%)\end{array}$ & $\begin{array}{l}\gamma^{\prime} \mathrm{T} \\
\left({ }^{\circ} \mathrm{C}\right)\end{array}$ & $\begin{array}{l}\gamma^{\prime \prime} \mathrm{T} \\
\left({ }^{\circ} \mathrm{C}\right)\end{array}$ & $\begin{array}{c}\mathrm{T} \\
\left({ }^{\circ} \mathbf{C}\right)\end{array}$ & $\begin{array}{c}\gamma^{\prime} \\
(w t \%)\end{array}$ & $\begin{array}{c}\gamma^{\prime \prime} \\
(w t \%)\end{array}$ & $\begin{array}{l}\gamma^{\prime} \mathrm{T} \\
\left({ }^{\circ} \mathrm{C}\right)\end{array}$ & $\begin{array}{l}\gamma^{\prime \prime} \mathrm{T} \\
\left({ }^{\circ} \mathrm{C}\right)\end{array}$ & $\begin{array}{c}\mathrm{T} \\
\left({ }^{\circ} \mathrm{C}\right)\end{array}$ & $\begin{array}{c}\gamma^{\prime} \\
(w t \%)\end{array}$ & $\begin{array}{c}\gamma^{\prime \prime} \\
(w t \%)\end{array}$ \\
\hline & & & & 780 & 4.9 & 11.8 & & & 780 & 6.3 & 9.6 \\
\hline & & & & 760 & 5.7 & 11.7 & & & 760 & 6.9 & 9.9 \\
\hline VAKIO & 4.82 & $8 / 4$ & 980 & 720 & 7 & 11.3 & 894 & 940 & 720 & 7.8 & 10.4 \\
\hline & & & & 620 & 9.5 & 10.7 & & & 620 & 9.3 & 11.4 \\
\hline & & & & 780 & 3.9 & 13.3 & & & 780 & 5.6 & 10.3 \\
\hline $\mathrm{VAP}$ & 5075 & 857 & 080 & 760 & 4.7 & 13.2 & 800 & 050 & 760 & 6.0 & 11.8 \\
\hline VARII & 3.015 & 851 & 989 & 720 & 6 & 12.8 & 890 & 950 & 720 & 7.0 & 12.2 \\
\hline & & & & 620 & 8.5 & 12.1 & & & 620 & 8.6 & 12.6 \\
\hline & & & & 780 & 5.1 & 13.2 & & & 780 & 5.6 & 11.6 \\
\hline & & & & 760 & 5.9 & 13 & 888 & & 760 & 6.5 & 12.2 \\
\hline VARI2 & 5.28 & 874 & 994 & 720 & 7.2 & 12.6 & 888 & 949 & 720 & 7.4 & 12.6 \\
\hline & & & & 620 & 9.6 & 11.8 & & & 620 & 9.1 & 13.0 \\
\hline
\end{tabular}

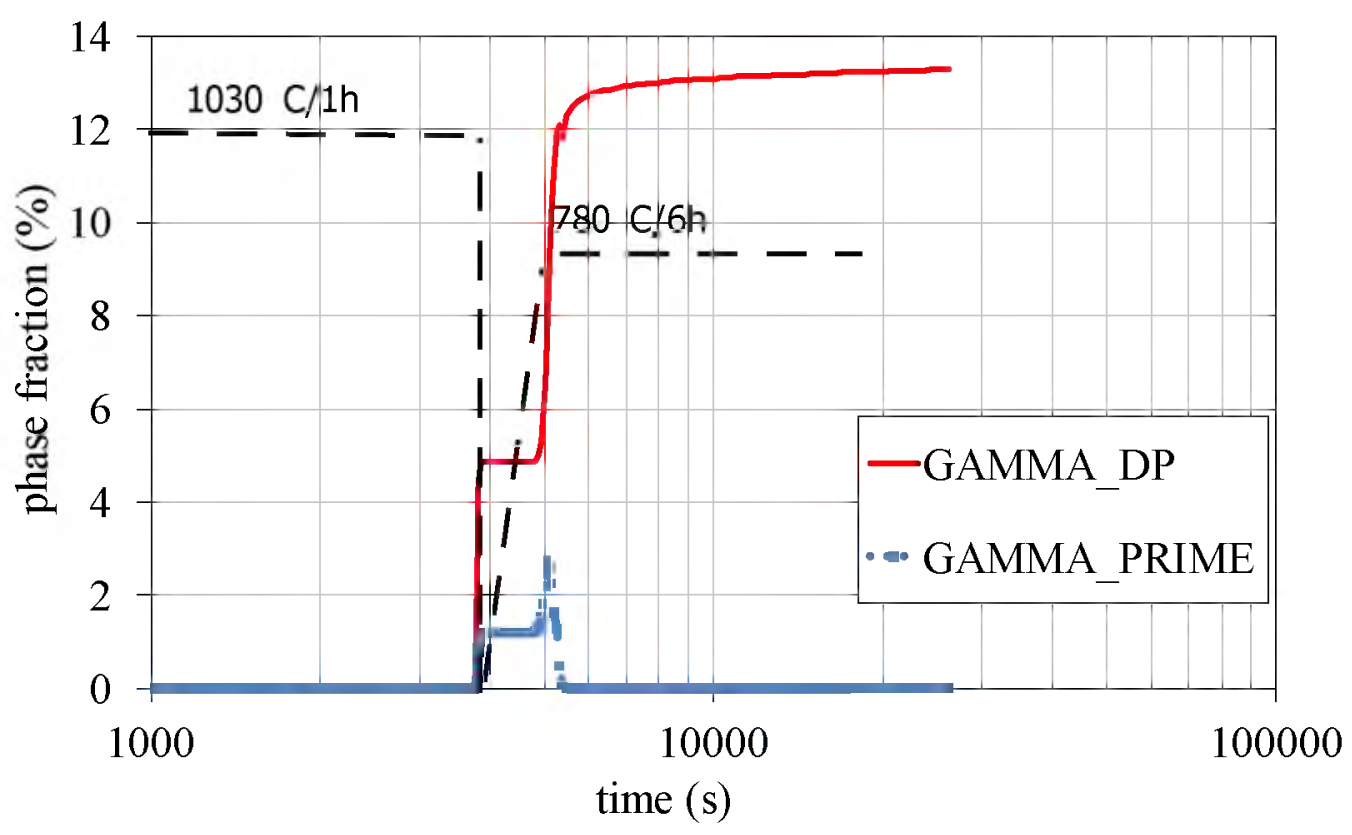

Figure 8. Phase fraction evolution in VAR10 composition calculated by MatCalc during heat treatment

In figure 9 the $\gamma$ " phase fraction evolution are reported for the compositions and heat treatments investigated. Calculated $\gamma^{\prime \prime}$ fractions are higher than that obtained at equilibrium conditions. This over-precipitation can be explained by considering that the nucleation of $\gamma^{\prime \prime}$ is faster than that of the other phases, i.e $\gamma^{\prime}$ and $\delta$. Increasing treatment time nucleates other stable phase and $\gamma^{\prime \prime}$ fraction will decrease. 


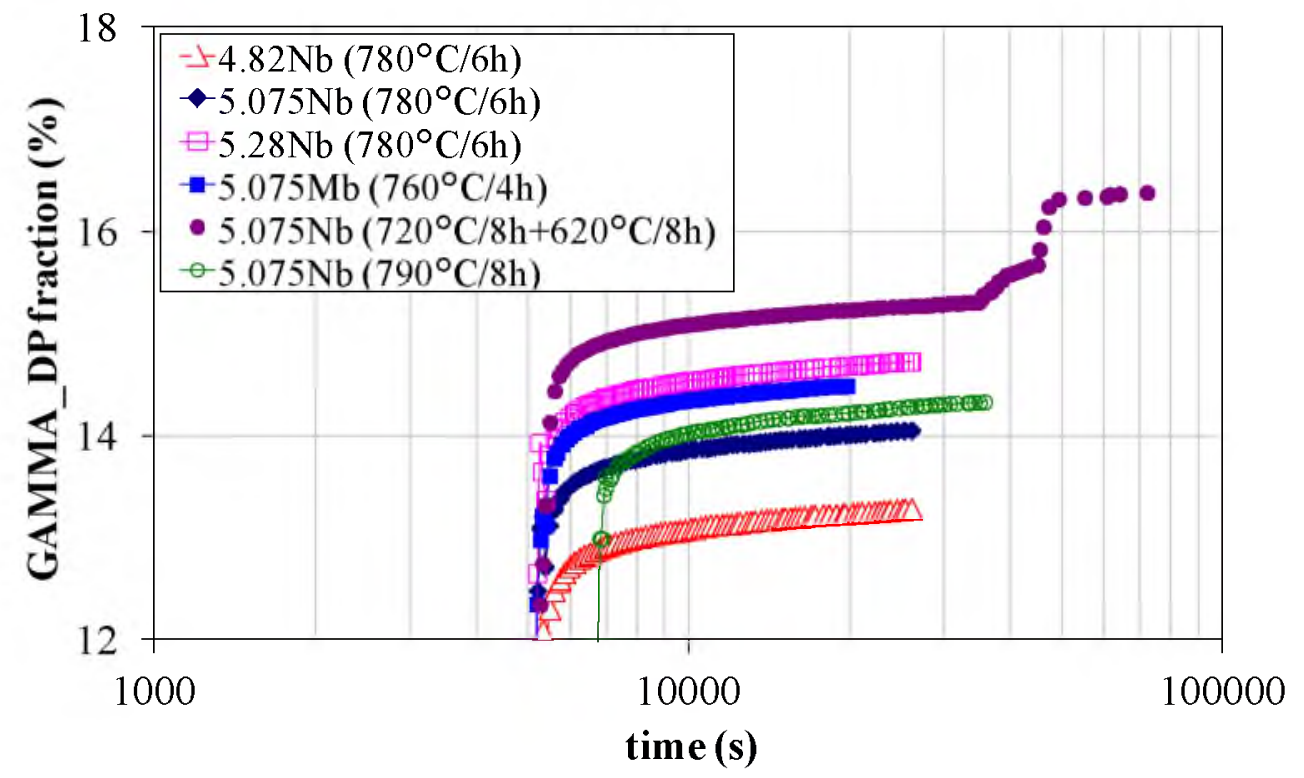

Figure 9. Phase fraction evolution during heat treatment calculated by MatCalc for all the investigated conditions

The evolution of $\gamma^{\prime \prime}$ particle size as function of time for all the compositions and heat treatments investigated is reported in figure 10 .

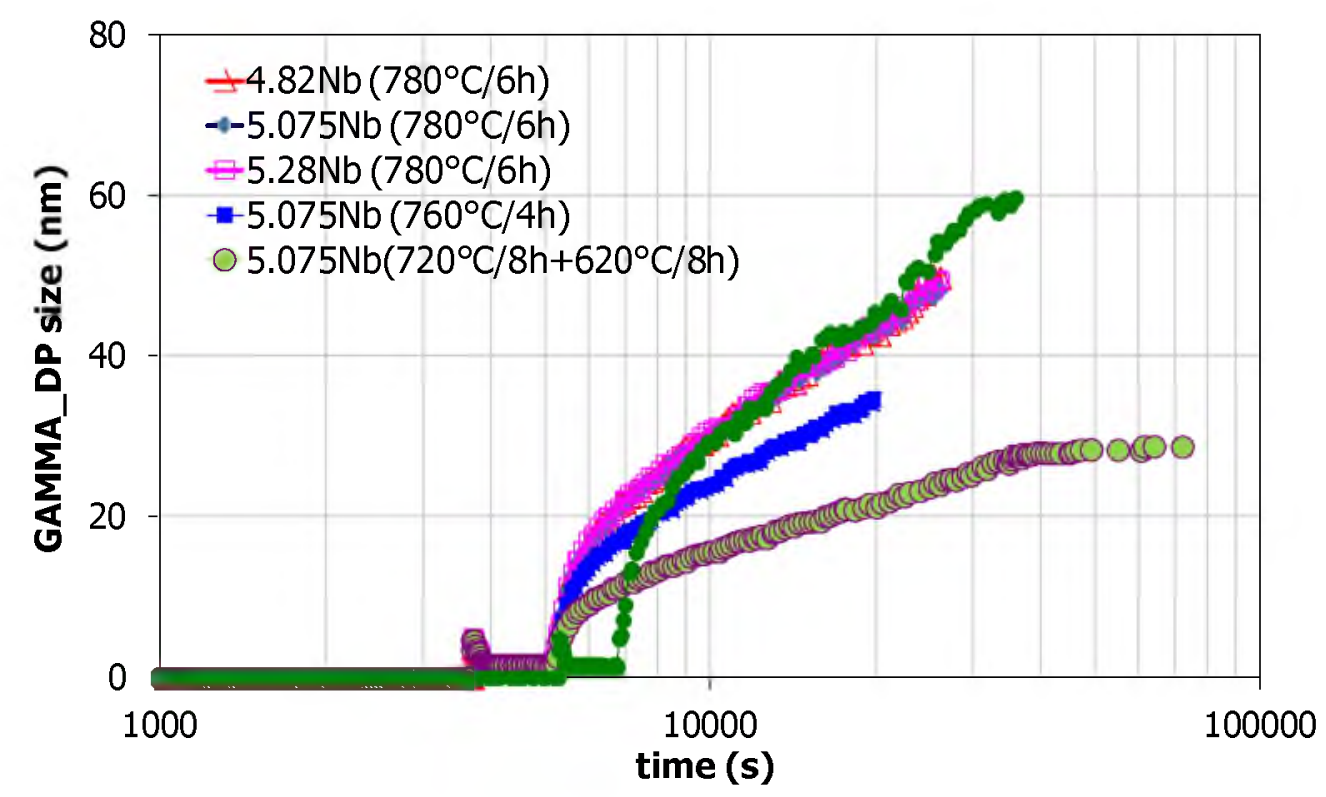

Figure 10. Precipitate size evolution during heat treatment calculated by MatCalc for all the investigated conditions

The results obtained by MatCalc kinetic simulations are summarised in the Table IV, in which $\gamma^{\prime}$ and $\gamma^{\prime \prime}$ fractions as well as their mean size are reported. $\delta$ phase is not formed and is not reported in the table. Data are compared to those obtained with JMatPro model with the "isothermal" 
feature, that well confirms data from calculated TTT diagrams. An example of TTP for the alloy VAR 11 is given in the figures 11 a-b respectively for $\gamma^{\prime \prime}$ an $\gamma^{\prime}$ phases.
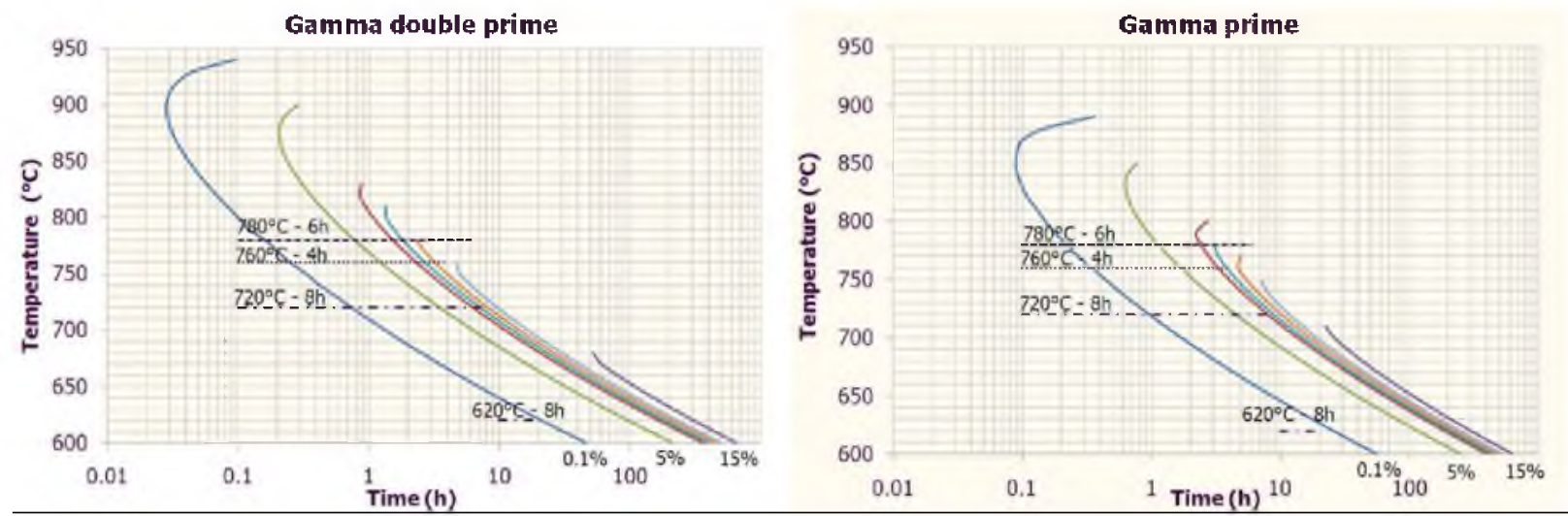

Figure 11. TTP diagrams calculated with JMatPro model of the alloy VAR11 for $\gamma$ ' and phases

Table IV. Comparison of precipitation MatCalc simulation results vs JMatPro results

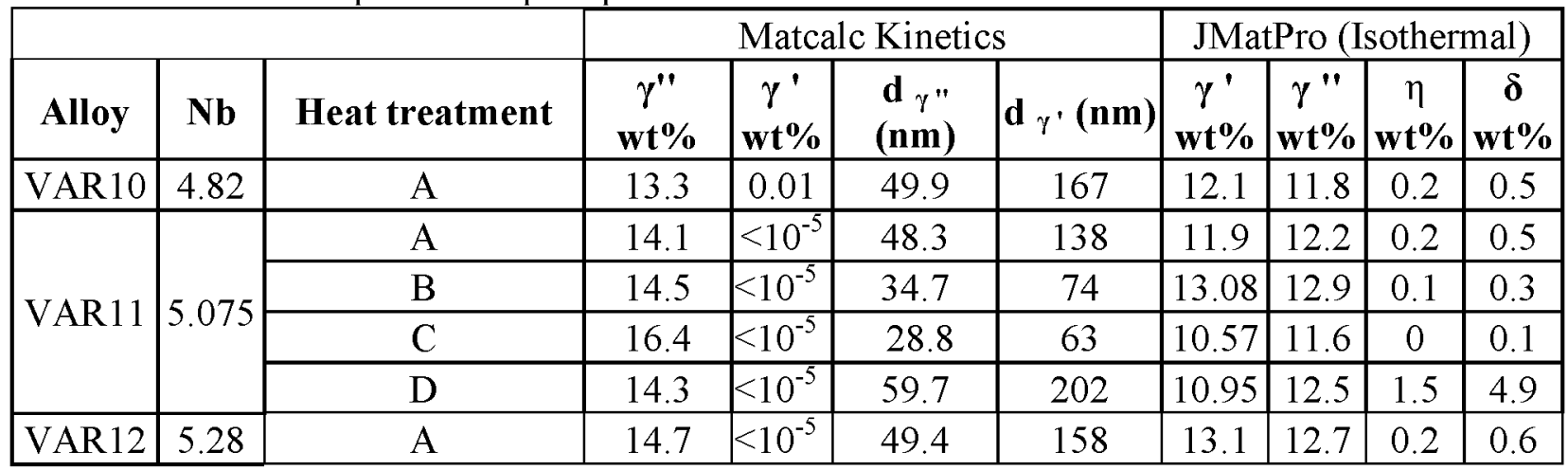

Results of simulation from MatCalc model give the following indications:

- for all the conditions $\gamma^{\prime}$ practically doesn't form;

- main phase is $\gamma$ ' with fraction that increases, as expected, by increasing $\mathrm{Nb}$ content;

- $\gamma$ ' size is ranging between 30 to $60 \mathrm{~nm}$. Differences are very limited regardless of $\mathrm{Nb}$ content;

- decreasing precipitation treatment temperature, the $\gamma$ ' fraction increases and its size decreases

According to JMatPro-model:

- gamma prime forms in an amount comparable and also higher to that of gamma double prime and without any apparent relationship with $\mathrm{Nb}$ content;

- gamma double prime increases with $\mathrm{Nb}$ content and calculated amounts are always lower than those obtained by MatCalc;

- some (very few) delta and eta phases are predicted to form at the temperature treatments; the fraction of these phases doesn't change with $\mathrm{Nb}$ content and decreases with reduction of ageing temperature;

- delta phase is increased up to about $5 \%$ with the ageing treatment performed at $790^{\circ} \mathrm{C}$ for 8 hours. 


\section{Discussion}

The overall results show that the variation in $\mathrm{Nb}$ content among the three alloys and the different ageing treatments significantly affects tensile properties. Yield and ultimate tensile strengths are increased, respectively, about $10 \%$ when $\mathrm{Nb}$ content is increased from $4.8 \%$ to $5.28 \%$ and $16 \%$ when the ageing temperature is decreased. Hardness measurements are mainly affected by the ageing conditions, although a weak trend is visible also varying the Niobium content, especially close to the external surfaces of the plates.

$\mathrm{Nb}$ content and ageing conditions define the fraction of $\gamma$ ' phase. The volume fraction of precipitates has not been experimentally determined, due to the complexity of the needed analysis. Nevertheless, an evaluation of the precipitation state of the investigated compositions, has been performed by means of thermodynamic and kinetic commercial models, JMatPro and MatCalc. Comparing the results of calculations with experimental results of metallographic investigations, some differences have been observed. In particular the following considerations concerning the MatCalc model can be done:

- MatCalc correctly predicts the presence of gamma double prime that is the main phase detected by TEM investigations;

- the fraction of $\gamma^{\prime}$ phase is negligible for all the conditions

- the size of precipitates is also well predicted being the calculated values in the range 30-60 nanometers and the experimental in the range $32-57 \mathrm{~nm}$; both series exhibit the same trend of experimental values.

- On the contrary Matcalc does not predict $\delta$ phase precipitation that has been experimentally observed in all the samples. This difference can be attributed to the fact that it evaluates precipitation starting from the nominal compositions. Actually, a Niobium enrichment at grain boundary is expected (due to micro-segregation during ingot solidification process, not completely homogenized during the solubilisation treatment) that locally favors delta phase precipitation.

Considering JMatPro model prediction:

- high volume fractions of both gamma prime and gamma double prime are predicted where gamma prime was not observed;

- delta phase precipitation prediction seems closer to the experimental results although some eta precipitation is also predicted but not observed.

- Precipitation kinetics are faster than those observed.

The setup of the model parameters starting from the experimental TTP diagrams reported in the literature [6-9] are very complex, due to differences in the chemical compositions and treatment conditions among the previous investigations.

In any case, the models can be helpful tools to set up and optimize chemical composition and heat treatment conditions to achieve target mechanical properties.

Relationships fitting experimental tensile behaviour with MatCalc calculated $\gamma$ ' fraction and size have been established as a function of precipitation features (figure 12). 


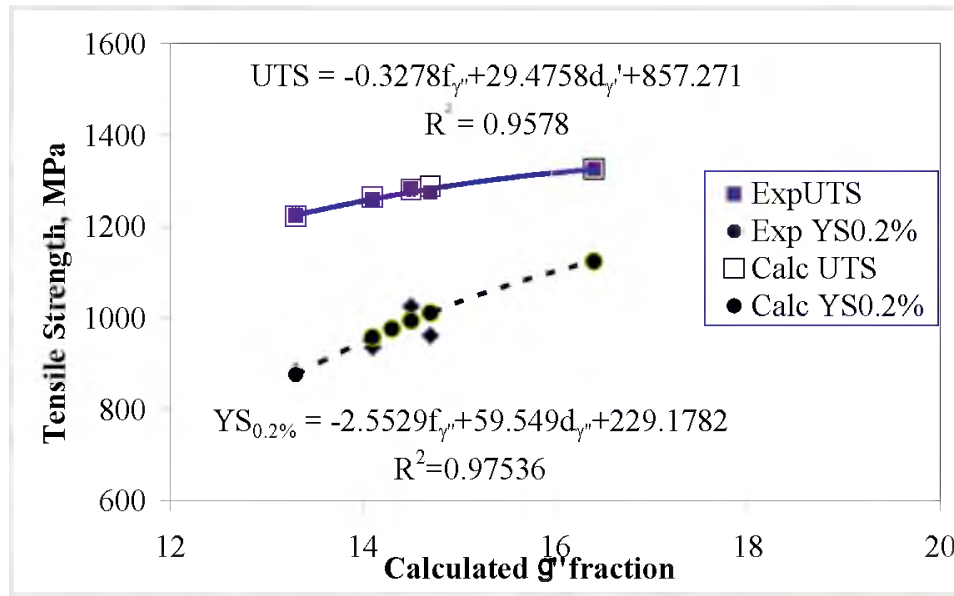

(a)

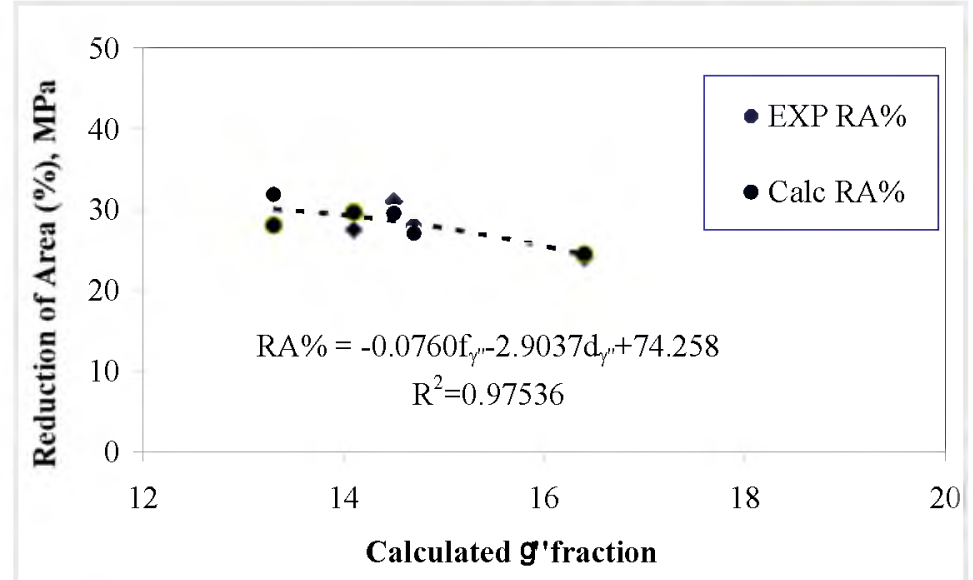

(b)

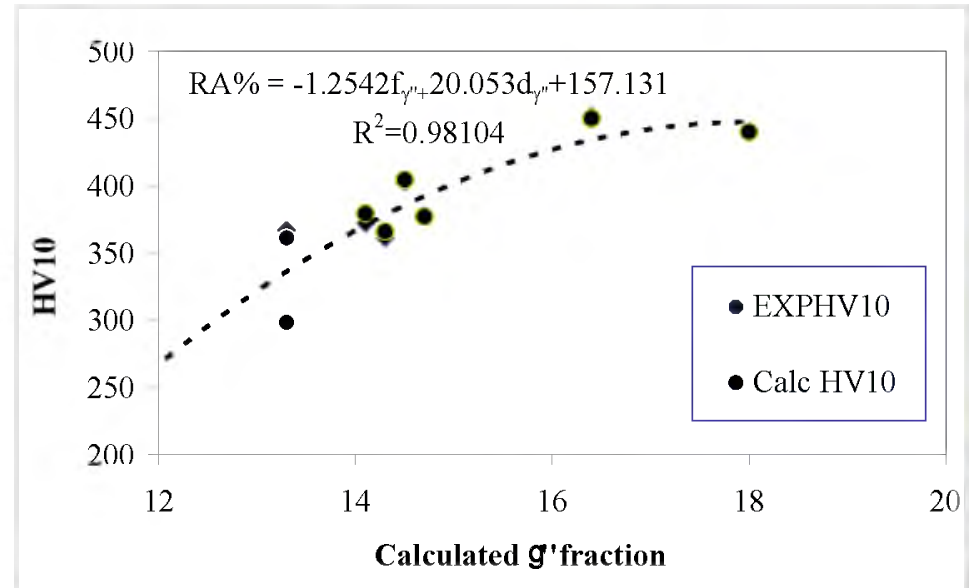

(c)

Figure 12. Effect of $\gamma$ ' fraction on (a) tensile strength, (b) ductility, (c) hardness

The presence of delta phase at grain boundaries, even when in low amount, has previously been documented as deleterious for stress corrosion resistance [10-11]. 


\section{Conclusions}

The overall results show that even small differences in $\mathrm{Nb}$ content and different ageing treatments significantly affect tensile properties. Yield and ultimate tensile strengths are increased about $10 \%$ when $\mathrm{Nb}$ content is increased from $4.8 \%$ to $5.28 \%$, and $16 \%$ when the ageing temperature is decreased. Hardness measurements are more affected by the ageing conditions, although a weak trend is visible varying the Niobium content, especially close to the external surfaces of the plates. Fracture energy is less sensitive to the product variants as the energy values quite comparable among all the plates.

Results have been interpreted by the use of thermodynamic and kinetic commercial models MatCalc and JMatPro. Predictions from both models are not fully consistent with experimental data. In any case the models are helpful tools to optimize chemical composition and heat treatment conditions to achieve the target properties.

\section{References}

1. NACE Standard Test Method MR0175-2000, "Sulfide Stress Corrosion Resistance Metallic Materials for Oilfield Equipment".

2. B. D. Craig, "Selection guidelines for corrosion resistant alloys in the oil and gas industry", NiDI Technical Series, 10073 (1995), 1-8.

3. E. L. Hibner and C. S. Tassen, "Corrosion Resistant OCTG's and Matching Age-Hardenable Bar Products for a Range of Sour Gas Service Conditions", Corrosion 2001, Paper No 1102 , (Houston, Texas: NACE International).

4. J. Svoboda et al, "Modelling of kinetics in multi-component multi-phase systems with spherical precipitates: I: Theory", Mater. Sci. Eng. A, 385 (2004), 166-174.

5. N. Saunders, "Phase diagram for Ni-based Superalloys", Superalloys, (TMS, Warrendale, PA: R. Kissinger et al, TMS 1996), 101-110.

6. A. Oradei-Basile, J.F. Radavich, "A Current T-T-T Diagram for Wrought Alloy 718", Int. Symp. on Superalloys 718, 625, 706 and Various Derivatives 1991, (TMS, Warrendale, PA: 1991), 325-335.

7. J. W. Brooks, P. J. Bridges “Metalurgical Stability of Inconel 718”, Superalloys, (TMS, Warrendale, PA: TMS 1996), 33-42.

8. X.Xie et al." TTT Diagram of a newly developed Nickel based superalloy - ALLVACß 718PLUSTM", Int. Symp. on Superalloys 718, 625, 706 and Various Derivatives, (TMS, Warrendale, PA: R. Kissinger et al, TMS 2005), 193-202.

9. V. Beaubois, et al, "Short Term Precipitation Kinetics of Delta Phase in Strain Free Inconel 718 Alloy", Materials Science and Technology, 20 (8) (2004), 1019-1026.

10. A. Aghajani et al., "The effect of Microstructure on the Stress Corrosion Cracking (SCC) of Alloy 718 in H2S environment", EUROCORR 2013, Estoril, Portugal.

11. M.G. Burke et al, "The effect of thermal treatment on SCC of Alloy 718: a structure properties study", Int. Symp. on Superalloys 718, 625, 706 and Various Derivatives 1994, (TMS, Warrendale, PA: R. Kissinger et al, TMS 1994), 763-772. 